\title{
Prediksi Jumlah Pendapatan Beasiswa PPA dan BBP Menggunakan Jaringan Syaraf Tiruan Backpropagation
}

\author{
Heru Satria Tambunan ${ }^{1}$, Indra Gunawan², Sumarno² \\ ${ }^{1}$ Program Studi Sistem Informasi,STIKOM Tunas Bangsa, Sumatera Utara, Indonesia \\ ${ }^{2}$ Program Studi Teknik Informatika, STIKOM Tunas Bangsa, Sumatera Utara, Indonesia \\ E-mail: ${ }^{1}$ heru@amiktunasbangsa.ac.id, ${ }^{2}$ indra@ amiktunasbangsa.ac.id, ${ }^{3}$ sumarno@amiktunasbangsa.ac.id
}

\begin{abstract}
Abstrak
STIKOM Tunas Bangsa merupakan Instansi dunia Pendidikan yang terletak di daerah Sumatera Utara, yang mana setiap semesternya membuka peluang untuk mahasiswa mendapatkan beasiswa PPA dan BBP, dari banyaknya jumlah mahasiswa maka dari itu tidak semua mahasiswa mendapatkan beasiswa, disebabkan minimnya kouta penerimaan beasiswa yang disediakan. setiap mahasiswa mempunyai kriteria yang hampir sama untuk mendapatkan beasiswa tersebut, dengan minimnya jumlah kouta penerima beasiswa Maka dari itu untuk menentukan jumlah kouta yang menerima beasiswa PPA di STIKOM Tunas Bangsa setiap tahunnya. Dalam memprediksi jumlah kouta penerima beasiswa menggunakan jaringan syaraf tiruan Backpropagation ini menggunakan data mulai tahun 2015 sampai dengan tahun 2019 data yang digunakan dari data sebelumnya yang telah diterima oleh kampus STIKOM Tunas Bangsa. Dengan adanya jaringan syaraf tiruan ini untuk memprediksi tahun 2020 jumlah penerima beasiswa PPA dan BBP di STIKOM Tunas Bangsa.
\end{abstract}

Kata Kunci: Beasiswa PPA, Jaringan Syaraf Tiruan Backpropagation, Matlab.

\begin{abstract}
STIKOM Tunas Bangsa is a world education institution located in the area of North Sumatra, where every semester for students who get PPA and BBP scholarships, from the number of students who come from it, not all students get scholarships, and at least get scholarships provided. Each student has the same criteria as the number of scholarships, with a minimum number of scholarship recipients. Therefore, to determine the number of participants who receive PPA scholarships in each country STIKOM Tunas Bangsa. In predicting the number of Kouta scholarship recipients using Backpropagation artificial nerves using data from 2015 to 2019 the data used from previous data has been received by the STIKOM Tunas Bangsa campus. With the existence of this artificial neural network to predict 2020 the number of PPA and BBP scholarship recipients at STIKOM Tunas Bangsa.
\end{abstract}

Keywords: PPA Scholarship, Backpropagation Artificial Neural Network, Matlab.

\section{PENDAHULUAN}

Dunia Teknologi sekarang ini semakin maju bahkan mendekai industri 4.0 yang mana dilakukan dengan cara otomatis. Teknologi informasi digunakan untuk mengelola data, memproses, sehingga menghasilkan menghasilkan informasi yang berkualitas, informasi yang diberikan untuk digunakan didunia industri, pendidikan, swasta dan pemerintahan yang mana tujuannya untuk mendapatkan hasil yang terbaik, Wiliam dan Li, penggunaan ANN dengan algoritma training back-propagation untuk melakukan prediksi pacuan kuda di Jamaika. ANN dengan jenis feed forward network atau Backpropagationyang digunakan dalam penelitian ini telah terbukti memberikan hasil yang baik untuk memprediksi.

Setiap kampus baik itu Universitas, Sekolah Tinggi, Politeknik atau Akademi pasti memberikan beasiswa terhadap mahasiswa yang berprestasi sebagai rewards mahasiswa tersebut, akan tetapi setiap kampus mendapatkan kouta penerimaan beasiswa tidak ada yang sama, ada jumlahnya yang besar dan ada yang kecil yang diberikan pemerintah. Beasiswa PPA merupakan beasiswa untuk mahasiswa yang berprestasi, tetapi tidak semua mahasiswa yang mendapatkan beasiswa tersebut dikarenakan jumlah kouta yang diberikan oleh pemerintah sedikit, padahal banyaknya mahasiswa yang mendaftar untuk mendapatkan beasiswa tersebut, dengan minimnya kouta yang diterima, maka dari itu tidak semua mahasiswa yang mendapatkannya. Dengan adanya metode Jaringan Syaraf Tiruan maka dengan ini dapat memprediksi berapa jumlah kouta yang akan di terima setiap tahunnya. Jaringan Syaraf Tiruan merupakan salah satu representasi buatan dari otak manusia yang selalu mencoba untuk mensimulasikan proses pembelajaran pada otak manusia. Istilah buatan digunakan karena jaringan syaraf ini diimplementasikan dengan menggunakan program komputer yang mampu menyelesaikan sejumlah proses perhitungan selama proses pembelajaran.

Beasiswa dapat dikatakan sebagai pembiayaan yang tidak bersumber dari pendanaan sendiri atau orang tua, akan tetapi iberikan oleh pemerintah, perusahaan swasta, kedutaan, universitas serta lembaga pendidik atau peneliti, juga dapat dari kantor tempat bekerja yang karena prestasi seorang karyawan dapat diberikan kesempatan untuk meningkatkan kapasitas sumber daya manusianya melalui pendidikan [1].

Jaringan Syaraf Tiruan (JST) merupakan suatu sistem pemrosesan informasi yang mempunyai karakteristik menyerupai jaringan syaraf biologis (JSB) Jaringan Syaraf Tiruan tercipta sebagai suatu generalisasi model matematis dari pemahaman manusia (human cognition) [2].

Jaringan saraf tiruan dibentuk sebagai generalisasi model matematika dari jaringan saraf biologis manusia, dengan asumsi bahwa:

1. Pemrosesan informasi terjadi pada banyak elemen sederhana (neuron). 
2. Sinyal dikirimkan di antara neuron-neuron melalui penghubung-penghubung.

3. Penghubung antar neuron memiliki bobot yang akan memperkuat atau memperlemah sinyal.

4. Untuk menentukan keluaran, Setiap neuron menggunakan fungsi aktivasi (biasanya bukan fungsi linier) yang dikenakan pada jumlah masukan yang diterima. Besarnya keluaran ini selanjutnya dibandingkan dengan suatu batas ambang.

Berdasarkan uraian diatas, maka penulis membuat sisterm berbasis jaringan syaraf tiruan yang mana digunakan untuk mmemprediksi berapa jumlah kouta beasiswa yang didapat setiap tahun.

\section{METODE PENELITIAN}

\subsection{Pengumpulan Data}

Dalam proses pembuatan penelitian ini penulis melakukan pengumpulan data dengan cara wawancara, observasi. Data yang digunakan untuk memprediksi kouta beasiswa mulai dari tahun 2012 - 2019 dan di ambil di kampus AMIK Tunas Bangsa. Berikut data input yang akan digunaka, dapat dilihat pada Tabel 1 dibawah ini:

Tabel 1. Data Input

\begin{tabular}{ccc}
\hline Tahun & Kouta PPA & Kouta BBP \\
\hline 2014 & 28 & 31 \\
2015 & 33 & 23 \\
2016 & 29 & 26 \\
2017 & 27 & 24 \\
2018 & 10 & 23 \\
\hline
\end{tabular}

\subsection{Proses Data}

Sebelum melakukan penginputan data maka melakukan transformasi. Data-data yang didapat akan di lakukan normalisasi sehingga menjadi data yang sama, yang data tersebut memiliki nilai range antara 0 dan 1 . Untuk mendapatkan menormalisasikan data tersebut agar menjadi 0 dan 1 maka menggunakan rumus $\min -\max$ [5]

$Z=\frac{X-X \min }{X \max -X \min } .(B \max -B M i n)+B$ Min dengan:

$\mathrm{X}=$ data input

$\mathrm{X}_{\min }=$ data $\mathrm{X}$ minimum

$\mathrm{X}_{\max }=$ data $\mathrm{X}$ maksimum

$\mathrm{B}_{\max }=$ batas atas interval

$\mathrm{B}_{\min }=$ batas bawah interval

Adapun tujuan fungsi normalisasi untuk menyamankan nilai data input yang di terima melalui observasi dan wawancara [9].

Proses normalisasi (preprocessing) yaitu Data yang akan dimasukkan ke dalam Jaringan Syaraf Tiruan harus dinormalisasi terlebih dahulu. Proses normalisasi dilakukan terhadap data input dan target. Normalisasi dilakukan menggunakan bantuan software Matlab dengan syntax: pn,meanp, stdp,tn,meant,stdt $]=\operatorname{prestd}(p, t)$. Dengan $p$ adalah matriks input pelatihan dan $t$ adalah matriks target [10]

\subsection{Alur Kerja}

Penelitian ini akan melalui dengan beberapa tahap untuk mendapatkan hasil prediksi kouta beasiswa untuk tahun berikutnya adalah sebagai berikut:

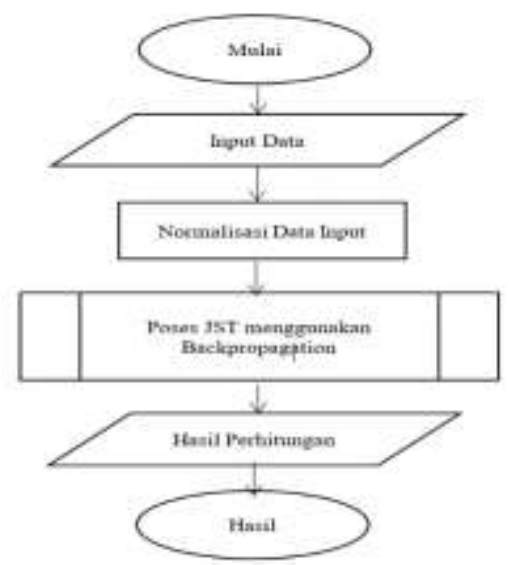

Gambar 1. Flowchart Kerja 


\section{ANALISA DAN PEMBAHASAN}

\subsection{Tahap pengujian}

Pada tahap ini melakukan pengujian data agar mendapatkan hasil prediksi nilai output yang akurat atau yang mendekati. Berikut hasil normalisasi dari data input yang digunakan, dilihat pada Tabel 2 dibawah ini:

Tabel 2. Data Normalisasi

\begin{tabular}{cccccc}
\hline Tahun & 2014 & 2015 & 2016 & 2017 & 2018 \\
PPA & 0.7261 & 0.9000 & 0.7609 & 0.6913 & 0.1000 \\
BBP & 0.8304 & 0.5522 & 0.6565 & 0.5870 & 0.5522 \\
\hline
\end{tabular}

\subsection{Tahap Perancangan Arsitektur}

Didalam memprediksi kouta beasiswa PPA dan BBP di tahun berikutnya penulis menggunakan pengujian dengan 4 model arsitektur yaitu dengan menggunakan arsitektur 4-2-1, 4-3-1,4-5-1, dan 4-71 yang masing arsitektur sama dengan menggunakan epoch 10000, berikut hasil arsitektur dalam pengujian untuk memprediksi kouta beasiswa PPA dan BBP:

Pada Tahap 1 menggunakan arsitektur 4-2-1 hasil trainning mendapatkan hasil MSEnya pada data testing 0.12464709 dengan hasil 50 dapat dilihat pada tabel 3 dan 4 dibawah ini

Tabel 3. Hasil Trainning

\begin{tabular}{llllll}
\hline No & Target & Output JST & Error & SSE & Hsl \\
\hline 1 & 0.1000000 & 0.0743000 & 0.0257000 & 0.0006605 & 1 \\
\hline 2 & 0.5521739 & 0.5885000 & -0.0363261 & 0.0013196 & 1 \\
\hline
\end{tabular}

Tabel 4. Hasil testing

\begin{tabular}{cccccc}
\hline No & Target & Output JST & Error & SSE & Hsl \\
\hline 1 & 0.5869565 & 0.5885000 & -0.0015435 & 0.0000024 & 1 \\
\hline 2 & 0.5173913 & 0.0181000 & 0.4992913 & 0.2492918 & 0 \\
\hline
\end{tabular}

Hasil grafik pengujian menggunakan arsitektur 4-2-1 di mana grafik tersebut menggunakan epoch 4147 untuk menuju goal hasilnya dapat dilihat pada gambar 2 dibawah ini.

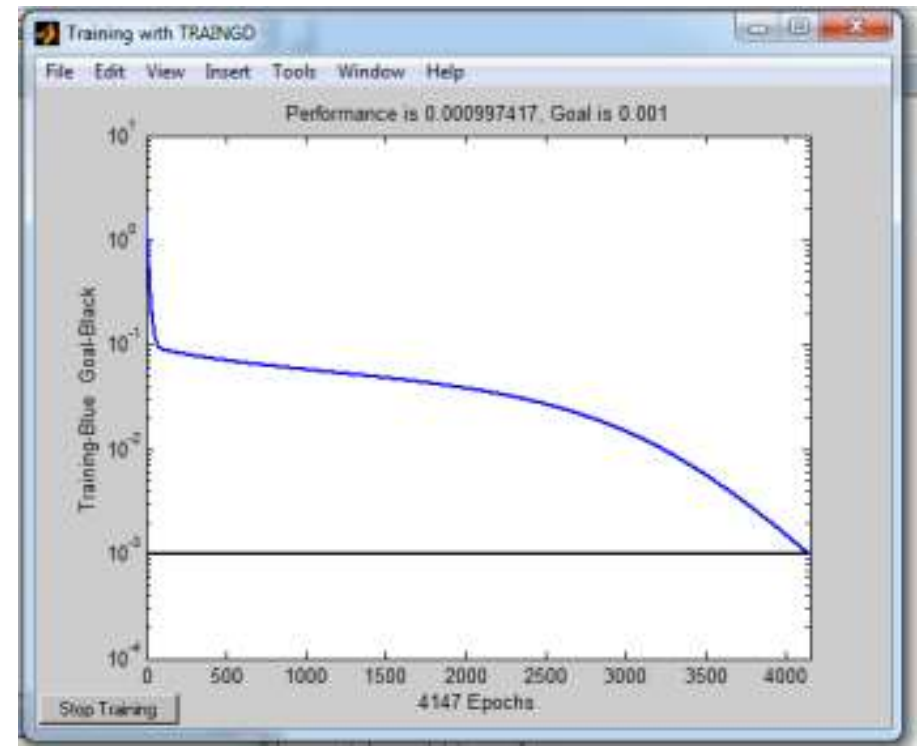

Gambar 2. Grafik Menuju Goal arsitektur 4-2-1

Selanjutnya untuk tahap 2 menggunakan arsitektur 4-3-1 hasil trainning mendapatkan hasil MSEnya pada data testing 0.14327593 dengan hasil 0 dapat dilihat pada tabel 5 dan 6 dibawah ini 
Tabel 5. Hasil Trainning

\begin{tabular}{cccccc}
\hline No & Target & Output JST & Error & SSE & Hsl \\
\hline 1 & 0.1000000 & 0.1384000 & -0.0384000 & 0.0014746 & 1 \\
\hline 2 & 0.5521739 & 0.5293000 & 0.0228739 & 0.0005232 & 1 \\
\hline
\end{tabular}

Tabel 6. Hasil Testing

\begin{tabular}{cccccc}
\hline No & Target & Output JST & Error & SSE & Hsl \\
\hline 1 & 0.5869565 & 0.5293000 & 0.0576565 & 0.0033243 & 0 \\
2 & 0.5173913 & -0.0148000 & 0.5321913 & 0.2832276 & 0 \\
\hline
\end{tabular}

Hasil grafik pengujian menggunakan arsitektur 4-3-1 di mana grafik tersebut menggunakan epoch 710 untuk menuju goal, dapat dilihat pada gambar 3 dibawah ini, .

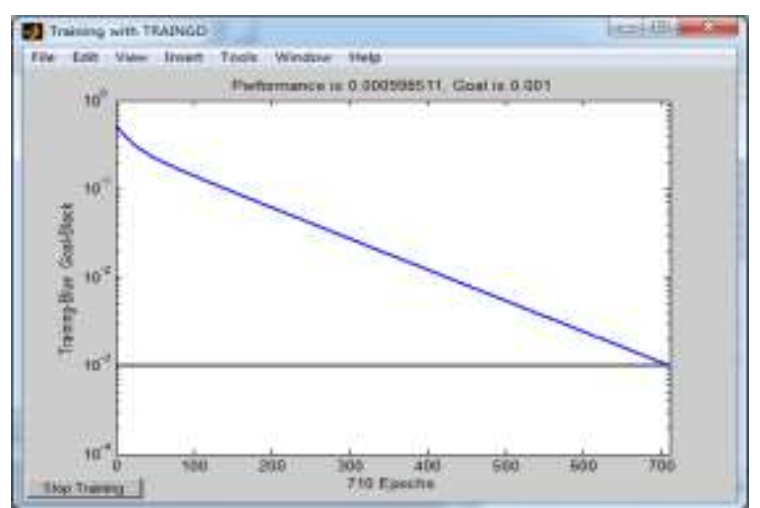

Gambar 3. Grafik Menuju Goal arsitektur 4-3-1

Pada tahap ke 3 ini menggunakan arsitektur 4-5-1 yang mana merupakan arsitektur terbaik dari ke 4 arsitektur pengujian sebelumnya, dapat dilihat pada tabel 7 dibawah ini untuk hasil trainning dan hasil testing

Tabel 7.Hasil Trainning

\begin{tabular}{cccccc}
\hline No & Target & Output JST & Error & SSE & Hsl \\
\hline 1 & 0.1000000 & 0.1232000 & -0.0232000 & 0.0005382 & 1 \\
2 & 0.5521739 & 0.5143000 & 0.0378739 & 0.0014344 & 1 \\
\hline
\end{tabular}

Tabel 8. Hasil Trainning

\begin{tabular}{llllll}
\hline No & Target & Output JST & Error & SSE & Hsl \\
\hline 1 & 0.5869565 & 0.5143000 & 0.0726565 & 0.0052790 & 1 \\
\hline 2 & 0.5173913 & 1.086200 & -0.5688087 & 0.3235433 & 1 \\
\hline
\end{tabular}

Hasil grafik pengujian menggunakan arsitektur 4-3-1 di mana grafik tersebut menggunakan epoch 710 untuk menuju goal, dapat dilihat pada gambar 4 dibawah ini.

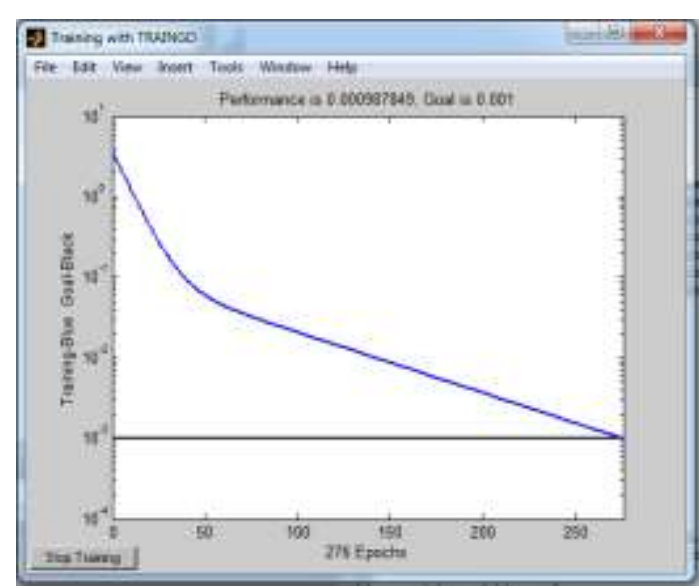

Gambar 4. Grafik Menuju Goal arsitektur 4-5-1

Adi Fitra Andikos | http://ejurnal.stmik-budidarma.ac.id/index.php/mib | Page 349 
Dari pengujian ke-3 diatas dari 4 pengujian tersebut dapat di disimpulkan bahwa arsitektur 4-5-1 merupakan arsitektur yang terbaik untuk memprediksi kouta beasiswa PPA dan BBP di Tahun berikutnya, dengan menggunakan 10000 epoch dan didalam 10000 epoch hanya membutuhkan 276 epoch dan MSE 0.00024751 dengan tingkat akurasi 100 dari data trainning dana untuk data testing menggunakan MSE 0.03116177 dengan tingkat akurasi 100, dapat dilihat pada tabel 9 sebagai berikut :

Tabel 9. Hasil Algoritma Backpropagation

\begin{tabular}{ccccccc}
\hline \multirow{2}{*}{ No } & \multirow{2}{*}{$\begin{array}{c}\text { Arsi } \\
\text { tektur }\end{array}$} & Epoch & MSE & Aku rasi & MSE & $\begin{array}{c}\text { Aku } \\
\text { rasi }\end{array}$ \\
\cline { 3 - 7 } & $4-2-1$ & 4147 & 0.000990037 & 100 & 0.124647094 & 50 \\
1 & $4-3-1$ & 710 & 0.00049502 & 100 & 0.06232355 & 0 \\
2 & $4-5-1$ & 276 & 0.00024751 & 100 & 0.03116177 & 100 \\
3 & $4-7-1$ & 173 & 0.00012375 & 100 & 0.01558089 & 50 \\
4 & & & & & & \\
\hline
\end{tabular}

Dengan data kategorisasi dapat dilihat pada tabel 10 dibawah ini

Tabel 10. Data katagorisasi

\begin{tabular}{crrc}
\hline No & & Keterangan & Error Minimum \\
\hline 1 & 1 & Benar & $0,05-0,001$ \\
\hline 2 & 0 & Salah & $>0,05$ \\
\hline
\end{tabular}

\section{KESIMPULAN}

Adapun kesimpulan dari jurnal ini bahwa dalam memprediksi jumlah pendapatan beasiswa PPA dan BBP menggunakan jaringan syaraf tiruan backpropagation dengan menggunakan arsitektur 4-5-1 yang terbaik dimana hanya membutuhkan 276 epoch dari 1000 epoch yang digunakan dan tingkat akurasinya 100 Arsitektur ini hanya menggunakan 1 hidden layer.

\section{REFERENSI}

[1] P. Oktavia, "Sitem Pendukung Keputusan Seleksi Penerimaan Beasiswa Dengan Metode Weighted Product Pada SMP Negeri 1 Parung Berbasis Web,” J. Inform. Univ. PAMULA, vol. 3, no. 2, pp. 80-86, 2018.

[2] A. Sudarsono, "Jaringan Syaraf Tiruan Untuk Memprediksi Laju Pertumbuhan Penduduk Menggunakan Metode Backpropagation (Studi Kasus Di Bengkulu),” J. Media Infotama, vol. 12, no. 1, pp. 61-69, 2016.

[3] Novia Lestari and L. L. Van FC, "Implementasi jaringan syaraf tiruan untuk menilai kelayakan tugas akhir mahasiswa (studi kasus di amik bukittinggi)," J. Teknol. Inf. Komun. Digit. Zo., vol. 8, no. 1, pp. 10-24, 2017.

[4] W. M. Dessy and A. Irawan, "Perbandingan Metode Jaringan Syaraf Tiruan Backpropagation Dan Learning Vector Quantization Pada Pengenalan Wajah,” J. Komput. dan Inform., vol. 1, no. 1, pp. 45-51, 2012.

[5] Y. A. Lesnussa, S. Latuconsina, and E. R. Persulessy, "Aplikasi Jaringan Saraf Tiruan Backpropagation untuk Memprediksi Prestasi Siswa SMA (Studi kasus: Prediksi Prestasi Siswa SMAN 4 Ambon),” J. Mat. Integr., vol. 11, no. 2, pp. 149-160, 2015.

[6] Y. D. Lestari, “Jaringan Syaraf Tiruan Untuk Prediksi Penjualan Jamur Menggunakan Algoritma Backropagation,” J. ISD, vol. 2, no. 1, pp. $40-46,2017$

[7] B. Satria, "Prediksi Volume Penggunaan Air PDAM Menggunakan Metode Jaringan Syaraf Tiruan Backpropagation," J. RESTI (Rekayasa Sist. dan Teknol. Informasi), vol. 2, no. 3, pp. 674-684, 2018.

[8] M. Yanto, S. Defit, and G. W. Nurcahyo, “Analisis Jaringan Syaraf Tiruan Untuk Memprediksi Jumlah Reservasi Kamar Hotel Dengan Metode Backpropagation,” J. KomTekInfo Fak. Ilmu Komput., vol. 2, no. 1, pp. 34-39, 2015.

[9] A. S. Ritonga and S. Atmojo, "Pengembangan Model Jaringan Syaraf Tiruan untuk Memprediksi Jumlah Mahasiswa Baru di PTS Surabaya (Studi Kasus Universitas Wijaya Putra),” J. Ilm. Teknol. Inf. Asia, vol. 12, no. 1, pp. 15-24, 2018.

[10] M. H. Dar, "Penerapan Metode Backpropagation Neural Network Untuk Memprediksi Produksi Air,” Maj. Ilm. INTI, vol. 12, no. 2, pp. 203-208, 2017. 